\title{
Knowledge, Attitude and Practice among Drivers in Trinidad, West Indies
}

\author{
Chavin D. Gopaul ${ }^{1 *}$, Aruna Singh-Gopaul ${ }^{2}$, Joan M. Sutherland ${ }^{3}$, Dave D. Chadee ${ }^{3}$ \\ ${ }^{1}$ Department of Para-Clinical Sciences, Faculty of Medicine, University of the West Indies, St Augustine, Trinidad and Tobago \\ ${ }^{2}$ North West Regional Health Authority, Port of Spain, Trinidad and Tobago \\ ${ }^{3}$ Department of Life Sciences, University of the West Indies, St. Augustine, Trinidad and Tobago \\ Email: *chavin.gopaul@gmail.com
}

How to cite this paper: Gopaul, C.D., SinghGopaul, A., Sutherland, J.M. and Chadee, D.D. (2016) Knowledge, Attitude and Practice among Drivers in Trinidad, West Indies. Journal of Transportation Technologies, 6, 405-419.

http://dx.doi.org/10.4236/jtts.2016.65033

Received: May 23, 2016

Accepted: October 9, 2016

Published: October 12, 2016

Copyright $\odot 2016$ by authors and Scientific Research Publishing Inc. This work is licensed under the Creative Commons Attribution International License (CC BY 4.0).

http://creativecommons.org/licenses/by/4.0/

\begin{abstract}
Few studies have been conducted on the incidence and factors which contribute to road traffic collisions in Trinidad. In order to fill this gap in knowledge, we conducted knowledge, attitudes and practice (KAP) study among drivers to determine which factors contributed to these accidents. A questionnaire was developed and administered using a cross-sectional approach among 3000 persons living in 5 different areas of Trinidad. The collected data were analysed using SPSS version 22, t-test and multivariate analysis. Of the 2998 respondents, at least 572 (19.1\%) had been involved in one or more road collisions. While only $46.7 \%$ of respondents always wore seat belts, approximately $93 \%$ believed strongly that their use was essential for safety-a 3-fold increase in that found in a previous study. The multiple regression analysis indicated that attitude and age were significantly associated with accidents and increased risk for accidents. The results showed that alcohol consumption, use of mobile phones while driving, speed, and age were significantly $(p>0.001)$ associated with accidents. In conclusion, most respondents were aware of traffic laws and regulations, but their knowledge and practice often diverged. However the improvement in attitude to seat-belt wearing suggests that a holistic driver education program may improve driver practice and adherence to the road traffic regulations in Trinidad.
\end{abstract}

\section{Keywords}

KAP, Trinidad, Road Collisions, Post Traumatic Stress

\section{Introduction}

Road traffic collisions (RTC) account for approximately 1.24 million deaths each year 
or 3400 per day, with the majority of deaths reported from low-income countries [1] or in rural communities in high-income countries [2]. With respect to global morbidity, up to 50 million have suffered injuries by road traffic collisions [1]. Globally, it is estimated that approximately 41.2 million persons have experienced an adjustment in life expectancy and in the quality of their life caused by road-related injuries and this figure is expected to rise. That is, in 2004, road traffic collisions were considered the ninth world leading cause of morbidity (health care burden) and this is expected to move to third position by 2030 [1].

This increase in the number of RTC can be attributed to 1) no new effective policies implemented to reduce the incidence, 2) no effective policies to reduce the number of vehicles on the road and 3) non-adherence or disregard of the road safety regulations or highway-code by young inexperienced drivers [1]-[3]. Within the Caribbean region, few studies have been conducted on RTCs with the exception of work done by Barreto et al. [4], Holder [5], St Bernard and Mathews [6] and Ramroop et al. [7].

Studies conducted in Trinidad and Tobago were primarily concerned with the pattern of mobile and seat-belt use by drivers [8] [9], mortality of young male drivers [4] [5], trends in road crashes and their economic burden [4]-[7] and various road fatality models were developed [4] [5] but all authors lamented the fact that the data sets used were of poor quality [3]-[9]. It is therefore difficult to understand how models that are useful in informing policy can be developed without robust epidemiological data. These models, although limited in scope, form the basis for launching studies on road traffic collisions prevention by the World Bank and the World Health Organization [1]. It should be noted that WHO [1] reported that Trinidad and Tobago did not have an agency with responsibility for road safety and accident prevention. However, the responsibility for coordinating road safety, education and collision prevention is carried out by various non-governmental organization (NGOs) while the Ministry of Health conducts campaigns aimed at increasing the use of seat-belts and discouraging driving under the influence of alcohol [1] [7] [8].

The knowledge, attitude and practice (KAP) survey is a powerful tool that can be used to determine these criteria in groups or populations regarding a wide range of social issues [10]. Many of these surveys have been conducted in the Caribbean region ranging in topics from public health epidemiology such as studies on dengue and leptospirosis [11] [12] to environmental issues such as climate change and tsunami readiness [13] [14] but to date no studies have been conducted on road traffic collisions. Therefore, the use of KAP surveys has now become a standard tool to evaluate population awareness and to determine behaviour change [15].

This study was conducted to evaluate the efficacy of current Ministry of Health and NGO programs aimed at reducing the number of road traffic accidents and therefore to reduce the number of deaths among young drivers in Trinidad and Tobago. No previous studies on driver's knowledge, attitudes and practices have been conducted, so this study attempts to fill this major gap in our knowledge and lay the foundation for future intervention measures. 


\section{Methodology}

The study was carried out between the months of May and December of 2012, in Trinidad and Tobago, a country with a population size of 1,324,699 (CSO [16]. The country is divided into 14 Regional Corporations and Tobago House of Assembly (see Figure 1). The regional corporations used for this study were located in Trinidad and were selected based on their high population densities, as well as to represent geographical spread within the island i.e. north, south, east and west (see Table 1). This approach ensured participants from different socio-economic strata, educational background, ethnicity and religious groups were represented. Six main locations were chosen including: Westmoorings (Diego Martin), Chaguanas (Chaguanas), Gasparillo (CouvaTabiquite-Talparo), Trincity (Tunapuna-Piarco), Princes Town (Princes Town) and San Fernando (San Fernando) (see Figure 1).

The formula by Daniel was used to calculate the sample size of 3000 persons cited in Elliott \& Armitage [17]. Variables were based on a confidence interval of $95 \%, p=0.5$, $\left.\mathrm{X}^{2}=0.05\right)$, a prevalence rate of $8 \%(12)$ and a precision of $2 \%$.
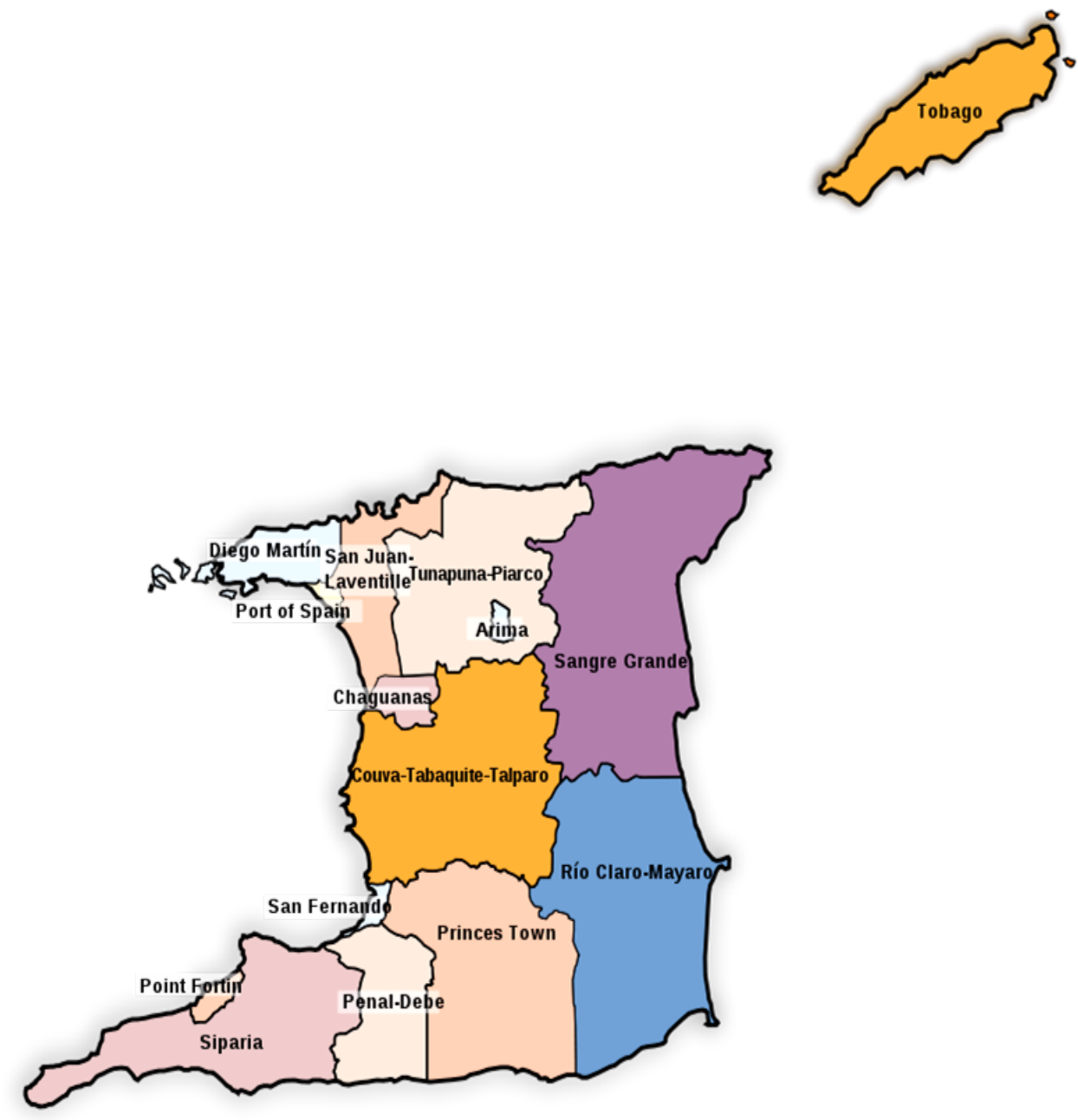

Figure 1. Regional corporations of Trinidad and Tobago. 
Table 1. Population of regional corporations of Trinidad.

\begin{tabular}{cc}
\hline Corporation & Population \\
\hline Port-of-Spain & 36,963 \\
San Fernando & 50,208 \\
Arima & 33,807 \\
Chaguanas & 84,216 \\
Point Fortin & 20,331 \\
Diego Martin & 101,703 \\
San Juan/Laventille & 155,606 \\
Tunapuna/Piarco & 211,741 \\
Sangre Grande & 74,546 \\
Couva/Tabaquite/Talparo & 185,243 \\
Princes Town & 101,134 \\
Mayaro/Rio Claro & 34,846 \\
Penal/Debe & 91,294 \\
Siparia & 86,251 \\
Total & $1,267,889$ \\
\hline
\end{tabular}

The questionnaire was developed and validated among drivers from the other geographic areas (see Figure 1) with similar demographics to the chosen study sites. Validation of the questionnaire was conducted among 300 residents (10\%) and based on feedback from the respondents minor changes were made to the questionnaire before they were administered. With a sample size of 3000 participants and six study sites selected, a total of 500 surveys were to be completed in each location. A cross-sectional study was conducted using a convenience sampling method which involved interviewing all residents who were home during the survey time, which was between the hours of 8 am to $4 \mathrm{pm}$. Only one member per household was interviewed after obtaining permission, but the selected person had to have a valid driver's license.

On completion of the study all questionnaires were collected and data encoded and organized into a database using SPSS [18] (Statistical Package for the Social Sciences) version 20. Chi-square tests were used to determine differences in age and gender G-test and T-tests were conducted to compare different factors, and univariate and multivariate analyses were used to determine other correlations with different study sites and ethnic variations or cross-cultural factors. All data was further analyzed to determine whether the selected variables were independent of each other and were significant at the 5\% level. Results are presented in tables.

\section{Results}

A total 2998 residents of Trinidad and Tobago participated in this study which is equivalent to a compliance rate $99 \%$, with only 2 persons refusing to participate. The 
minimum age was 17 years and no maximum age limit was set. The majority of the participants from Westmoorings, Chaguanas, Gasparillo, Trincity, Princes Town, and San Fernando were educated (89.9\%) and also employed (83.5\%). Most participants had achieved at least secondary level schooling (54.7\%), or tertiary education (35.2\%), as reflected in a large number being employed (83.5\%) in either public service (30.5\%), self-employed (16.2\%), or the private sector (36.8\%), as shown in Table 2.

The largest group of persons participating in this survey belonged to the age group 30 - 39 years (30.1\%) followed by 20 - 29 years $(29.8 \%), 40$ - 49 years $(21.1 \%)$, above $>50$ years $(13.3 \%)$, and $17-19$ years $(5.7 \%)$. The majority of the participants were either married (45.9\%) or single (33.3\%), with Christians (47.6\%) and Hindus (37.0\%) dominating the religious domain (see Table 2).

Most participants 2894 (96.5\%) demonstrated either a moderate $(79.0 \%)$ or a high (17.5\%) level of knowledge of road traffic regulations (Table 3). A significant number of respondents $(70.7 \%)$ correctly indicated the major contributory factors for road traffic collisions, which included driver's noncompliance, lack of awareness about traffic regulations and very high driving speeds (Table 3 ).

When participants were questioned about the use of seat belts (Table 4), 61.8\% strongly agreed that they should be used. Though, when it came to judging their attitudes/motivations behind using them, 53\% were in support of their use for passengers, while others thought that drivers should insist that passengers wear their seat belts while in their vehicles (31\%).

When asked about the use of phones while driving, $0.6 \%$ suggested the practice was very safe, while $0.8 \%$ felt that it was just safe, but the majority, $46.1 \%$ and $48.2 \%$ thought that use of mobile phones was unsafe and very unsafe, respectively (Table 4).

On drinking and driving a significant number $(p>0.002)$ of respondents were concerned (94.6\%), however only $33.1 \%$ were always concerned while $61.5 \%$ were only sometimes concerned and 5.3\% were not concerned at all about drinking and driving.

On speeding, only $35.9 \%$ were always concerned about speed regulations but the majority (57.7\%) were only sometimes concerned and $6.4 \%$ never concerned. In line with the Trinidad Roads Act, the second schedule, the preferred and recommended speed in Trinidad roads is $80 \mathrm{~km} / \mathrm{H}$, except for buses, trucks, goods and vehicles (65 $\mathrm{Km} / \mathrm{H}$ ), and trailers and tractors which should be driven between $35 \mathrm{Km} / \mathrm{H}$. Only $56.1 \%$ of the participants knew the correct speed limit. Other respondents suggested that the recommended speed was $60 \mathrm{~km} / \mathrm{H}(12.9 \%), 70 \mathrm{~km} / \mathrm{H}(21.3 \%)$ and $90 \mathrm{~km} / \mathrm{H}$ $(9.7 \%)$.

Each of the ten listed potential causes of accidents was identified by more than half of respondents.

Respondents practice (Table 5) regarding observing speed limits were slightly worse than their reported attitudes in that only $32.1 \%$ of participants reported always obeying speed limits while the remainder either sometimes or never obeyed them.

Fewer than half (46.7\%) of respondents always wore seat belts though $61.8 \%$ reported very strong approval of them. 
Table 2. Socio-demographics of the study participants $(n=2998)$.

\begin{tabular}{|c|c|c|c|}
\hline & & Frequency & Percent \\
\hline \multirow{5}{*}{ Age } & $17-19$ & 171 & 5.7 \\
\hline & $20-29$ & 894 & 29.8 \\
\hline & $30-39$ & 903 & 30.1 \\
\hline & $40-49$ & 633 & 21.1 \\
\hline & $>50$ & 398 & 13.3 \\
\hline \multirow{4}{*}{ Marital Status } & Never Married & 1000 & 33.3 \\
\hline & Married & 1377 & 45.9 \\
\hline & Divorced & 237 & 7.9 \\
\hline & Common-law relationship & 384 & 12.8 \\
\hline \multirow{4}{*}{ Religion } & Christian & 1428 & 47.6 \\
\hline & Hindu & 1111 & 37 \\
\hline & Muslim & 373 & 12.4 \\
\hline & Other & 86 & 2.9 \\
\hline \multirow{2}{*}{ Gender } & Male & 1917 & 63.9 \\
\hline & Female & 1081 & 36.1 \\
\hline \multirow{4}{*}{ Ethnicity } & Afro-Trinidadian & 497 & 16.6 \\
\hline & Indo-Trinidadian & 1803 & 60.1 \\
\hline & Mixed & 654 & 21.8 \\
\hline & Other & 44 & 1.5 \\
\hline \multirow{6}{*}{ Level of Education } & Nursery/Kindergarten & 8 & 0.3 \\
\hline & Primary & 246 & 8.2 \\
\hline & Secondary & 1641 & 54.7 \\
\hline & Tertiary & 1056 & 35.2 \\
\hline & None & 15 & 0.5 \\
\hline & Other & 32 & 1.1 \\
\hline
\end{tabular}

Table 3. Knowledge of the participants about road traffic regulations $(n=2998)$.

\begin{tabular}{lcc}
\multicolumn{1}{c}{ Variable } & Number & Percentage \% \\
\hline Knowledge & 525 & 17.5 \\
1) High & 2369 & 79.0 \\
2) Moderate & 104 & 3.5 \\
3) Low & & \\
Reasons for traffic road accidents & 360 & 12.0 \\
1) Driving too fast & 306 & 10.2 \\
2) Lack of awareness about traffic laws & 213 & 7.1 \\
3) Non-compliance with the law & 2119 & 70.7 \\
4) All the above & & \\
\hline
\end{tabular}


Table 4. Participant attitude towards road traffic regulations and accidents $(n=2998)$.

\begin{tabular}{|c|c|c|}
\hline Variable & Number & Percentage \% \\
\hline \multicolumn{3}{|l|}{ Convinced about use of seat belts } \\
\hline 1) Very strong & 1852 & 61.8 \\
\hline 2) Strong & 930 & 31 \\
\hline 3) Weak & 216 & 7.2 \\
\hline \multicolumn{3}{|l|}{ Use of mobile phones while driving } \\
\hline 1) Very safe & 16 & 0.6 \\
\hline 2) Safe & 25 & 0.8 \\
\hline 3) Undecided & 131 & 4.4 \\
\hline 4) Unsafe & 1381 & 46.1 \\
\hline 5) Very unsafe & 1445 & 48.2 \\
\hline \multicolumn{3}{|l|}{ Concerned about Driving while drunk } \\
\hline 1) Never & 159 & 5.3 \\
\hline 2) Sometimes & 1846 & 61.5 \\
\hline 3) Always & 993 & 33.1 \\
\hline \multicolumn{3}{|l|}{ Concerned about High speeds } \\
\hline 1) Never & 192 & 6.4 \\
\hline 2) Sometimes & 1730 & 57.7 \\
\hline 3) Always & 1076 & 35.9 \\
\hline \multicolumn{3}{|c|}{ The following factors always cause accidents: } \\
\hline 1) Driving when tired & 2294 & 76.5 \\
\hline 2) Drinking and driving & 1846 & 61.5 \\
\hline 3) Following a vehicle too closely & 1995 & 66.5 \\
\hline 4) Driving too fast & 1730 & 57.7 \\
\hline 5) Taking medication and driving & 2009 & 67.0 \\
\hline 6) Taking illegal drugs and driving & 1910 & 63.7 \\
\hline 7) Poorly maintained roads & 2245 & 74.8 \\
\hline 8) Traffic congestion & 2212 & 73.7 \\
\hline 9) Defective vehicle & 2243 & 74.8 \\
\hline 10) Texting while driving & 1907 & 63.6 \\
\hline
\end{tabular}


Table 5. Practice by participants towards road traffic regulations and injuries $(\mathrm{n}=2998)$.

\begin{tabular}{lcr}
\hline & Number & Percenta \\
\hline Observe speed limit & 1845 & 61.5 \\
1) Sometime & 962 & 32.1 \\
2) Always & 191 & 6.0 \\
3) Never & & 46.7 \\
Comply with wearing seat-belt & & 31.6 \\
1) Always & 1400 & 18.7 \\
2) Sometimes & 947 & 3 \\
3) Usually & 561 & \\
4) Never & 90 &
\end{tabular}

Prior involvement in RTAs in last five years

$\begin{array}{lcc}\text { 1) None } & 1090 & 36.4 \\ \text { 2) One } & 385 & 12.8 \\ \text { 3) Two } & 144 & 4.8 \\ \text { 4) Three } & 32 & 1.1 \\ \text { 5) More than Four } & 11 & 0.4 \\ \text { 6) No response } & 1336 & 44.6\end{array}$

Environmental conditions during accident
1) Poor weather
2) Poor visibility
3) Poor road surface conditions
4) Absence/malfunction of a traffic light
5) Good conditions

145

140

4.7

174

63

Risk behaviours for RTAs
1) Intoxication
2) Multitasking
3) Disobedience of the driving regulations
4) Negligence of the other driver
5) Bad luck
6) Other

10 
Only $36.4 \%$ of respondents had not been involved in an RTA in the previous 5 years, while $44.6 \%$ gave no response and 572 persons $(19.1 \%)$ admitted to having been involved in at least one accident, and 11 persons to having had more than four. Of those who had been involved in accidents only $15.9 \%$ admitted to hazardous driving behavior (intoxication, multitasking, or disobedience of regulations) while $82.5 \%$ either blamed the other driver or "bad luck".

The DSM-IV approach in diagnosing acute stress disorder elaborates on post-traumatic reactions that occur between 2 and 28 days after RTA and incorporates a number of symptoms including dissociation, hyper-arousal, avoidance, and intrusion. Using simple logistic regression, the four variables identified individual life behaviour after RTA and predicted if the encounter would change their normal activities. The simple logistic model used in this case is based on a linear relationship between the natural logarithm (ln) of the odds of an event and a numerical independent variable. The form of this relationship is as follows:

$$
\operatorname{Ln}\left(\frac{p}{1-p}\right)=\beta_{0}+\beta_{1} X_{1}+\beta_{2} X_{2}+\cdots+\beta_{k} X_{k}
$$

where

$p$ is the proportion of successes,

$L$ is the $\ln$ (odds of event),

$X$ is the independent variable,

$\beta_{0}+\beta_{1}$ are the $Y$-intercept and the slope, respectively.

Preliminary score of foreshortened and irritability future symptoms of Post-Traumatic Stress Disorder (PTSD), and early degree of vulnerability after involvement of RTAs were examined. Hyper-activity was indicated by questionnaire items, (difficulty paying attention to details, inability to sustain attention on tasks, difficulty in facing up to problems and frequent shifts from one uncompleted activity to another), combined to predict that $64 \%$ of individuals had recuperated from the accident, while $36 \%$ remained affected by the RTAs. Using multiple regression in predicting continuous variable totals, which is also a measure of PTSD, it was observed that $38.1 \%(R=0.618)$ of the respondents were distracted or dissociated from their normal way of life (that is, they experienced depersonalisation and de realisation), while those who experienced intrusion were approximately $53.4 \%$ (constant reminder of the events, flashbacks, dissociative reaction and feeling distressed). Lastly, individuals who had been subjected to avoidance were $32.6 \%$ (individuals who were described as unable to overcome the events or external reminders of the events). Those that showed much more than usual behaviours to all the questionnaire items (acutely anxious) were 5.6\%, those who behaved normally or showed no more than usual behaviour were $6.6 \%$, while those who remain unaffected with PTSD were 6.2\% and those whose lives were affected more than usual were $13.4 \%$. As such, in evaluating the statistical correlation between PTSD and increased RTAs, the findings establish that both destruction and increased activity are linked to RTA ( $p=0.002,0.028$ respectively), while intrusion and avoidance from 
normal livelihood are non-significant ( $p=0.02$ and 0.0625 respectively) at 0.05 level as shown in Table 6.

The logistic model results predicted that over $80.9 \%$ of those involved in RTC were likely to experience the observed PTSD related factors. The observed groups and predicted probabilities are as shown below.

Years of research and evaluation have stipulated that traffic accidents and injuries cannot be stopped completely. However, the frequency of accidents and severity of injuries can be minimised and significantly eliminated by adhering to simple protective measures. This can include obeying traffic speed regulations and the use of seat belts. Findings from this study demonstrate that risk predisposing factors to road accidents include road conditions, driver's attitude to traffic regulations and car conditions. As such, the logistic regression model predicted that those who have a history of RTCs have a high probability of experiencing PTSD, as evidenced by psychological factors such as dissociation, intrusion, avoidance and hyperactivity, which can result in an increased risk of road accidents. In this case, dissociation is a psychological disorder where a person separates himself from the effects of his thoughts, memories, as well as

Table 6. Regression analysis.

\begin{tabular}{|c|c|c|c|}
\hline Factor & $\%$ & $T$ & $p=95 \% C I$ \\
\hline Dissociation & 38.1 & 2.83 & 0.002 \\
\hline \multicolumn{4}{|l|}{ - Depersonalisation } \\
\hline \multicolumn{4}{|l|}{ - Derealisation } \\
\hline Hyperactivity & 64.0 & 0.07 & 0.028 \\
\hline \multicolumn{4}{|c|}{ - Competence making decisions } \\
\hline \multicolumn{4}{|l|}{ - Usefulness since RTA } \\
\hline \multicolumn{4}{|c|}{ - Enjoying daily activities } \\
\hline \multicolumn{4}{|l|}{ - Facing up problems } \\
\hline \multicolumn{4}{|c|}{ - Feeling reasonably happy } \\
\hline Avoidance & 32.6 & 0.25 & 0.0425 \\
\hline \multicolumn{4}{|c|}{ - Inability to overcome the events } \\
\hline \multicolumn{4}{|c|}{ - External reminders of the events } \\
\hline Intrusion & 53.8 & 1.64 & 0.02 \\
\hline \multicolumn{4}{|c|}{ - Constant reminder of the events } \\
\hline \multicolumn{4}{|c|}{ - Flashbacks, dissociative reaction } \\
\hline - Feeling distressed & & & \\
\hline
\end{tabular}


the sense of self-identity. Hyperactivity, on the other hand, is a psychological disorder where the individual is anxious and has an abnormal form of enhanced physical energy which makes the person highly active, unable to relax and think straight. Research conducted by Anon (2012) shows that avoidance is a maladjustment coping mechanism that enables a person to avoid dealing with the reality if it entails highly traumatic experience. Additionally, intrusion entails a memory disorder that merges the past and the present in a manner that a person undergoes a repeated experience of the past traumatic event.

With respect to the traffic lights compliance, $15.6 \%$ admitted that upon seeing the red light they were more likely to defy it, while a large majority $(84.6 \%)(p>0.002)$ indicated that they would approach it slowly and stop. However, the results showed that most people who drove past the red light (16.6\%) were either late $(2.2 \%)$, wanted to save time (5.4\%), frustrated about stopping again (5.6\%), enjoyed the fun of beating the red light (1.8\%) and other reasons (0.6\%).

The results of the univariate analysis indicated that age was a significant factor when considering the occurrence of road collisions among the participants while car speed and place of residence were not significant factors contributing to road collisions (Table 7). However, the number of years of driving or experience was found significantly associated with exposure risk to traffic collisions.

When subjected to a multivariate analysis (using a multiple linear regression model), showed that alcohol consumption, use of mobile phones while driving, speed, and age were significantly $(p<0.001)$ associated with accidents. Whereas, when the reference group ( $>30$ years of age) was compared with the younger age group, the younger age group was found at greater risk of accidents than persons over 30 years of age.

Table 7. Factors that influence exposure to traffic road accidents among respondents in Trinidad $(n=2998)$.

\begin{tabular}{lcc}
\hline \multicolumn{1}{c}{ Variables } & $\mathrm{T}$ & $p$-value \\
\hline Age & & \\
$\leq 30$ & 3.97 & \\
Place of residence & & \\
City location & 0.23 & 0.001 \\
Rural location & & \\
Having a driving license & & \\
Yes & 1.62 & 0.542 \\
No & & \\
Speed in the highway & & \\
$>60$ & 0.08 & \\
$>90$ &
\end{tabular}




\section{Discussion}

Our KAP study has illustrated potentially rich information that can be obtained by using a large number of motor vehicle drivers to determine the major factors associated with road traffic collisions in Trinidad and Tobago. The fact that about 19\% had been involved or experienced motor vehicle accidents suggests that a frequency distribution or probability distribution can be estimated, and the risks of an adverse impact can be calculated and used to make risk-based judgements. In addition, because of the high proportion of educated and legal aged drivers, these findings indicate that illiteracy and under age driving played no part in shaping the drivers' attitudes and practices towards road safety and traffic regulation. In fact their high education levels and knowledge of traffic regulations did not influence compliance with the regulations and drivers continued to flout these by driving while intoxicated, while using mobile phones and at high speeds, major factors which contribute to road traffic accidents in Trinidad. This finding is very similar to that found by Blincoe et al. [19] and Pierro et al. [20].

The present results clearly indicate that most drivers consider themselves knowledgeable about road traffic laws, however their knowledge was not always put into practice. Similarly, Nan [21], Anon [22], Waylen and McKenna [23], and Yilmaz and Eray [24], also found a divergence between knowledge of traffic laws and adherence in practice. For example, the present study showed that approximately $93 \%$ of drivers support the use of seat-belts while only $46.7 \%$ always wear them. However this is a 3 -fold improvement in attitude to seat-belt wearing over that found in a previous study [25] which indicated that $31.6 \%$ considered seat-belts important to save lives and should be worn at all times. This seat belt requirement is outlined in article 43 (A) of the 1994 Trinidad and Tobago Motor Vehicles (Seat Belt Assemblies) Regulations, Subsection 9 (clauses 1 - 6) which spells out the passenger requirements and the fines for non-compliance.

The results of the univariate analysis showed that the duration or number of years of driving experience was significantly linked to the frequency of road traffic collisions (Table 7). That is the drivers with a limited number of years of driving experience had a greater tendency to become involved in collisions after an initial period with fewer collisions. Other studies have reported opposite findings with drivers who have less than "four years of driving experience" demonstrating a positive attitude and complying with road traffic rules, regulations and speed limits, while those with more years of experience were less likely to follow these regulations. That is novice drivers were more likely to adhere to traffic regulations because of the fear of accidents and limited driving experience. This observation is supported by the fact that the mean speed of novice participants fell between $60 \mathrm{~km} / \mathrm{H}$ and $90 \mathrm{~km} / \mathrm{H}$ on the highways. However, the results from Nakagawa et al. [26] and the present study indicate that less experienced drivers are more likely to drive at higher speeds and generally to disobey road traffic regulations, although persons above 50 years of age are less likely to break the law [19]-[24] [26].

Results from the multivariate analysis showed a significant association between age 
and road traffic accidents in Trinidad. The older participants who were above 30 years of age were less likely to take risks that may lead to accidents when compared with young and/or new drivers who were 30 years of age or less.

The present results showed large numbers of young people used the roads, drove aggressively and with a higher tendency to drive dangerously. Similar results were reported by Nakagawa et al. [26] and Elliott and Armitage [17] who indicated that the demographic causing the most collisions belonged to the under 30 age category. This age group displayed attitudes which lead to excess alcohol use, non-compliance with seat belt regulations and high speed driving, which demonstrated a total disregard for traffic regulations and laws. In general the results found a significant relationship with age and the frequency of road traffic accidents in Trinidad.

These results show that there is a strong relationship between individual attitudes and road collisions. Some workers have shown that drivers' attitudes were the most important factor leading to the significant increase in the number of road traffic accidents [25] [27]-[29]. Similarly, during the present study, drivers' attitudes towards traffic laws were found to be the main cause of road collisons and contribute to $76 \%$ of all collisions in Trinidad. This is despite the drivers' awareness and knowledgeable about basic traffic laws and regulations many driver signore some of the basic road and safety regulations. For example, the motor vehicles and road traffic (mobile devices) regulations of 2010, section $4(1-2)$ prohibits drivers from using or holding a handheld telephone device but many still break this law although fines include $\$ 10,000 \mathrm{TT}$ or 5 years' imprisonment or both. Heavy fines seem not to serve as a deterrent nor does education in a small number of individuals.

\section{Conclusion}

In this research, the KAP questionnaire was developed and tested among 3000 drivers from five locations in Trinidad, West Indies. The analyzed results indicated that 2998 drivers responded, of which circa 19\% were actually involved in road traffic accidents. The results showed that alcohol consumption, use of mobile phones while driving, speed, and age were significantly associated with accidents. In addition, most participants had achieved at least secondary level schooling (54.7\%), or tertiary education (35.2\%), but these levels of education played no part in shaping the drivers' attitudes and practices or compliance with road safety and traffic regulations. The 3 -fold improvement in attitude to seat-belt wearing over that found in a previous study gives hope that with appropriate public campaigns, this may be translated into improved compliance (in practice). It similarly suggests that with a more holistic driver education program, the large percentage of drivers who are only sometimes concerned about driving at high speed or while drunk can be persuaded to always be concerned and to obey the traffic laws and regulations of Trinidad and Tobago.

\section{Authors' Statement}

Ethical approval was obtained from the University of the West Indies (St. Augustine). 
The authors have no conflicts of interest to declare.

\section{References}

[1] WHO (2013) Global Status Report on Road Safety 2013. WHO Press, Luxembourg.

[2] Godavarthy, R.P. and Russell, E.R. (2016) High-Risk Rural Road Safety Study and Determining the Crash-Reduction Factors for High-Risk Rural-Road Usage. Journal of Transportation Technologies, 6, 1-8. http://dx.doi.org/10.4236/jtts.2016.61001

[3] Gopaul, C. (2015) Factors Which Contribute to Road Traffic Accidents in Trinidad, West Indies. PhD Thesis, University of the West Indies, in Prep.

[4] Barreto, S.M., Miranda, J.J., Figueroa, J.P., Schmidt, M.I., Munoz, S., Kuri-Morales, P.P. and Silva, J.B. (2012) Epidemiology in Latin America and the Caribbean: Current Situation and Challenges. International Journal of Epidemiology, 41, 557-571. http://dx.doi.org/10.1093/ije/dys017

[5] Holder, Y. and Lewis, M.J. (1987) Epidemiological Overview of Morbidity and Mortality. In: Health Conditions in the Caribbean, Pan American Health Organization, Washington DC, 22-61.

[6] St. Bernard, G. and Matthews, W.A. (2003) Contemporary Analysis of Road Traffic Crashes, Fatalities and Injuries in Trinidad and Tobago. Injury Control and Safety Promotion, 10, 21-27. http://dx.doi.org/10.1076/icsp.10.1.21.14104

[7] Ramroop, S., Turner, M.C., Bynoe, R., Garner, M.J., Clarke, R., Krewak, D. and Francia, M. (2009) Injury Surveillance in Trinidad: An Accident and Emergency Based Injury Surveillance System at the San Fernando General Hospital. West Indian Medical Journal, 58, 118123.

[8] Olukoga, A. Legall, G. and Odekunle, A. (2011) Mobile Phone Use by Drivers in Trinidad and Tobago, West Indies. Journal of Public Health and Epidemiology, 3, 115-120.

[9] Olukoga, A., Legall, G. and Odekunle, A. (2011) Pattern of Seat-Belt Use by Drivers in Trinidad and Tobago. BMC Research Notes, 4, 1-6. http://dx.doi.org/10.1186/1756-0500-4-201

[10] Vandamme, E. (2009) Concepts and Challenges in the Use of Knowledge-Attitude-Practice Surveys: Literature Review. Department of Animal Health Institute, Institute of Tropical medicine, Antwerp.

[11] Rosenbaum, J., Nathan, M.B., Ragoonanansingh, R., Rawlins, S.C., Gayle, C., Chadee, D.D. and Lloyd, L. (1995) Community Participation in Dengue Prevention and Control: A Survey of Knowledge, Attitudes and Practice in Trinidad and Tobago. American Journal of Tropical Medicine and Hygiene, 53, 111-117.

[12] Mohan, A.R.M. and Chadee, D.D. (2011) Knowledge, Attitudes and practice of Trinidadian Households Regarding Leptospirosis and Related Matters. International Health, 3, 131-137. http://dx.doi.org/10.1016/j.inhe.2011.03.002

[13] Rawlins, S.C., Chen, A., Rawlins, J., Chadee, D.D. and Legall,G.(2007) A Knowledge, Attitudes and Practice Study on the Issue of Climate Change/Variability Impacts and Public Health in Trinidad and Tobago, St. Kitts and Nevis. West Indian Medical Journal, 56, 115121. http://dx.doi.org/10.1590/S0043-31442007000200003

[14] Kanhai, L.K., Singh, D., Lauckner, B., Ebi, K.L. and Chadee, D.D. (2016) Knowledge, Attitude and Practice of Coastal Communities in Trinidad and Tobago about Tsunamis. Natural Hazards, 81, 1349-1372. http://dx.doi.org/10.1007/s11069-015-2138-3

[15] Easteban, M., Tsimopoulou, V, Mikami, T., Yun, N.Y., Suppasri, A. and Shibayama, T. (2013) Recent Tsunami Events and Preparedness: Development of Tsunami Awareness in 
Indonesia, Chile and Japan. International Journal of Disaster Risk Reduction, 5, 84-97. http://dx.doi.org/10.1016/j.ijdrr.2013.07.002

[16] Central Statistical Office (2011) Population and Housing Census Register. Ministry of Planning and Development, Trinidad and Tobago Government, Port of Spain.

[17] Elliott, M. and Armitage, C. (2009) Promoting Drivers' Compliance with Speed Limits: Testing an Intervention Based on the Theory of Planned Behaviour. Journal of Neuropsychology, 100, 111-132. http://dx.doi.org/10.1348/000712608x318626

[18] SPSS Inc (2012) SPSS Base 22.0 for Word User Guide. SPSS Inc., Chicago.

[19] Blincoe, K., Jones, A., Sauerzapf, V. and Haynes, R. (2006) Speeding DRIVERS' attitudes and Perceptions of Speed Cameras in Rural England. Accident Analysis and Prevention, 38, 371-378. http://dx.doi.org/10.1016/j.aap.2005.10.008

[20] Pierro, A., Giacomantonio, M., Pica, G., Giannini, A.M., Kruglanski, A.W. and Higgins, E.T. (2013) Persuading Drivers to Refrain From Speeding: Effects of Message Sidedness and Regulatory Fit. Accident Analysis and Prevention, 50, 917-925. http://dx.doi.org/10.1016/j.aap.2012.07.014

[21] Nan, X. (2004) The Influence of Liking for a Public Service Announcement on Issue Attitude. Communication Research, 35, 503-528.

[22] Horvath, C., Lewis, I. and Watson, B. (2012) The Beliefs Which Motivate Young Male and Female Drivers to Speed: A Comparison of Low and High Intenders. Accident Analysis and Prevention, 45, 334-341. http://dx.doi.org/10.1016/j.aap.2011.07.023

[23] Waylen, A.F. and McKenna, F.P. (2008) Risky Attitudes Towards Road Use in Pre-Drivers. Accident Analysis and Prevention, 40, 905-911. http://dx.doi.org/10.1016/j.aap.2007.10.005

[24] Yilmaz, V. and Eray, C.E. (2008) A Model for Explanation of Personal Attitudes toward Traffic of Candidate Drivers Attending Drivers' Courses: Risky Candidate Driver's Attitude Model. Transportation Research Part F, 11, 233-241. http://dx.doi.org/10.1016/j.trf.2007.10.003

[25] Hassan, H.M. and Abdel-Aty, M.A. (2013) Exploring the Safety Implications of Young Drivers' Behavior, Attitudes and Perceptions. Accident Analysis and Prevention, 50, 361370. http://dx.doi.org/10.1016/j.aap.2012.05.003

[26] Nakagawa, Y., Kaechang, P. and Yasuhiko, K. (2013) Elderly Drivers' Everyday Behavior as a Predictor of Crash Involvement-Questionnaire Responses by Drivers' Family Members. Accident Analysis and Prevention, 50, 397-404. http://dx.doi.org/10.1016/j.aap.2012.05.014

[27] Falk, B. (2010) Do Drivers Become Less Risk-Prone after Answering a Questionnaire on Risky during Driving. Accident Analysis and Prevention, 42, 235-244. http://dx.doi.org/10.1016/j.aap.2009.08.003

[28] Ma, Y., Lou, Y. and Wang, Y. (2010) Road Traffic Accidents Model and Its Application Based on Driver's Self-Mistakes. Journal of Transportation Systems Engineering and Information Technology, 10, 101-105. http://dx.doi.org/10.1016/S1570-6672(09)60059-3

[29] Pinsky, I., Erich, L., Robert, P. and Ronaldo, L. (2001) Drinking and Driving: Pre-Driving Attitudes and Perceptions among Brazilian Youth. Journal of Alcohol Drug Dependency, 62, 231-237. http://dx.doi.org/10.1016/S0376-8716(00)00173-3 
Submit or recommend next manuscript to SCIRP and we will provide best service for you:

Accepting pre-submission inquiries through Email, Facebook, LinkedIn, Twitter, etc. A wide selection of journals (inclusive of 9 subjects, more than 200 journals)

Providing 24-hour high-quality service

User-friendly online submission system

Fair and swift peer-review system

Efficient typesetting and proofreading procedure

Display of the result of downloads and visits, as well as the number of cited articles

Maximum dissemination of your research work

Submit your manuscript at: http://papersubmission.scirp.org/

Or contact jtts@scirp.org 